\title{
Correction to: Phase angle in systemic sclerosis: a marker for pulmonary function and disease severity
}

\author{
Antonietta Gigante ${ }^{1} \cdot$ Maria Ludovica Gasperini $^{1} \cdot$ Andrea lacolare $^{1} \cdot$ Danilo Alunni Fegatelli $^{2} \cdot$ Annalisa Villa $^{1}$. \\ Maurizio Muscaritoli ${ }^{1} \cdot$ Edoardo Rosato $^{1}$ (D)
}

Published online: 20 April 2020

(C) International League of Associations for Rheumatology (ILAR) 2020

\section{Correction to: Clinical Rheumatology https://doi.org/10.1007/s10067-020-05034-2}

The name of the author of the original published version of this article was presented incorrectly. The author name "Antonietta Gigantea" should have been presented as "Antonietta Gigante". This has been correctly presented above.

The original article has been corrected.

Publisher's note Springer Nature remains neutral with regard to jurisdictional claims in published maps and institutional affiliations.

The online version of the original article can be found at https://oi.org/ $10.1007 /$ s10067-020-05034-2

Edoardo Rosato

edoardo.rosato@uniroma1.it

1 Department of Translational and Precision Medicine, Sapienza University of Rome, Viale dell'Università 37, 00185 Rome, Italy

2 Department of Statistical Science, Sapienza University of Rome, Rome, Italy 